\title{
De-convoluting the European Commission Cosmos
}

\author{
Manfred Kurz* \\ Regulatory Affairs, Mylan GmbH, Zurich, Switzerland
}

\begin{abstract}
The centralized registration procedure allows medicinal products to be prescribed and sold in all 27 Member States of the European Community. The aim of this article is to shed light on the complex rules governing the grant of marketing authorization at the European Commission level.

The 'Decision Making Process' surrounding the Commission is not well understood because during the review of a new marketing authorization application the focus is on the scientific evaluation carried out by the European Medicines Agency (EMA). However, after receipt of a positive opinion by the EMA the subsequent approval process is not purely an administrative act. Knowledge of the scope, sequence of procedural steps and associated timelines at the Commission is key for accurate project planning which in turn is a prerequisite for timely product launch.
\end{abstract}

Keywords: European commission; Decision making process; European medicines agency

\section{Introduction}

Medicinal products require a marketing authorization prior to marketing and sales. In the European Union (EU), the European Commission (EC) is the legal entity that grants single marketing authorizations. These marketing authorizations for innovative medicines are valid throughout the Community following a centralized, high-level scientific assessment by the European Medicines Agency (EMA). According to Annex 1 of Regulation (EC) No 726/2004, Community authorizations are mandatory for medicinal products developed by means of recombinant DNA technology, advanced therapy medicinal products and new active substances intended for treatment of certain diseases (acquired immune deficiency syndrome, cancer, neurodegenerative disorder, diabetes, autoimmune diseases and other immune dysfunctions, viral diseases) as well as for orphan drugs [1].

\section{EMA and Centralized Procedure}

The EMA is the administrative body coordinating the evaluation of marketing authorizations in the EU. The assessment itself is carried out by distinct review panels composed of expert regulators from the national competent authorities of the EU Member States. Concerning medicines for human use, the Committee for Medicinal Products for Human Use (CHMP) is responsible for the scientific determination of suitable quality, safety and efficacy. The CHMP is composed of a chair, Member State representatives, as well one member and an alternate member nominated by Iceland/Norway plus up to five co-opted members to provide additional expertise in a particular scientific area. Member State representatives and alternate representatives come from each of the $27 \mathrm{EU}$ Member States. They have expertise in evaluation of medicines and they serve on the committee for a renewable 3-year term [2].

Besides this scientific analysis, the EMA is also involved in the supervision and safety monitoring of medicinal products post licensure. For more specialized tasks, and to support the CHMP in balancing risks and benefits of medicinal products as well in the formulation of opinions, the EMA has established several additional committees. Likewise created and organized as the CHMP. These include the Committee for Orphan Medicinal Products (COMP), Committee on Herbal Medicinal Products (HMPC), Pediatric Committee (PDCO), and Committee for Advanced Therapies (CAT) and Committee for Medicinal Products for Veterinary Use (CVMP). Recently, the EMA has inaugurated its seventh committee, the Pharmacovigilance Risk Assessment Committee (PRAC) [3,4].

In terms of interplay, some of these committees (eg. COMP, CVMP) carry out assessment of applications (eg. orphan drug designations, veterinary medicinal product registrations) independently from the CHMP. Other committees (e.g. PDCO, CAT) represent aassessment team's orginating from expert groups (eg. CAT for advanced medicinal product; PDCO for pediatric investigations) which are assigned by the CHMP; the CHMP itself acts as peer reviewer and a CHMP coordinator who manages the review process also facilitates the flow of information between the CAT / PDCO and CHMP.

It should be noted that for instance the evaluation of advanced medicinal products may also require interaction with other committees such as PDCO and COMP as well as other scientific working groups. Likewise, PDCO may collaborate with other groups at the EMA such as Pharmaco Vigilance Working Party (future PRAC) etc. However, while arriving at the end of the examination procedure the CHMP is the body responsible for drafting the final opinion and via the EMA sharing the assessment with the EC. Although there is extensive overlap among the scientific commitees within the EMA dialogue between the Agency and $\mathrm{EC}$ and other EU insitutions is primarily established through the EMA / CHMP [5,6].

Of note, an application for a marketing authorization of a medicinal product for human use under the 'centralized procedure' must be submitted to the EMA and not to the EC [7]. The same is true for lifecycle submissions - variations to the marketing authorization - which need to be filed to EMA for assessment. As with the original marketing authorization, the approval of variations is also within the competency of the EC.

The EMA review procedure for marketing authorization applications is a well-defined and transparent process, which follows a standard timetable. An initial validation period requires 10 working days, during which EMA may ask for additional data or clarification

*Corresponding author: Manfred Kurz, Regulatory Affairs, Mylan GmbH Zurich, Switzerland, Email: manfred.kurz@mylan.com

Received May 28, 2012; Accepted July 10, 2012; Published August 17, 2012

Citation: Kurz M (2012) De-convoluting the European Commission Cosmos. Pharmaceut Reg Affairs 1:103. doi:10.4172/2167-7689.1000103

Copyright: (c) 2012 Kurz M. This is an open-access article distributed under the terms of the Creative Commons Attribution License, which permits unrestricted use, distribution, and reproduction in any medium, provided the original author and source are credited. 
in order to decide on the acceptability of the submission. Following the start of the review procedure, preliminary assessments from the 'Rapporteurs' - two CHMP members assigned by the EMA along with their review teams who check the application on behalf of the CHMP - are sent to the Applicant and to the Member States at Day 80 of the procedure. At Day 120, the CHMP adopts a consolidated list of questions (LoQ). These questions are objections to the approval of the product that were identified in the Rapporteurs' preliminary assessments or by the review of these assessments by the Member States. In addition to the objections, the LoQ contains overall conclusions from the evaluation of the scientific data. The LoQ is sent to the Applicant by the EMA. A clock stop for three months, but maximally up to six months is allowed for the Applicant to respond to the LoQ. A request for an extension beyond three months must provide justifications and should be addressed to the CHMP Chairman. At Day 121, the Applicant's responses, including revised summary of product characteristics (SPC), labeling and package leaflet texts (in English language), are submitted and the review clock is restarted. After receipt of the responses, the CHMP adopts a timetable for the evaluation of the responses. The Rapporteurs evaluate the responses and prepare a joint assessment report, sent to the CHMP at Day 150. At Day 180, the CHMP adopts a 'list of outstanding issues' (LoOI) to be addressed by the Applicant. These 'outstanding issues' represent persisting objections to the approval of the product. Because the EU-Risk Management Plan (RMP) must be finalized prior to the opinion, any RMP related issues are included in the LoOI [8].

If there are important 'outstanding issues', an oral explanation may be necessary. A one-month preparation period prior to the CHMP hearing may be requested by the Applicant. During this time, the company usually generates written responses to the LoOI and prepares a presentation for the oral explanation. An additional one-month extension in submission of the written responses can be granted only upon provision of appropriate scientific grounds to be reviewed and agreed upon by the CHMP. The request for an extension beyond one month should be submitted promptly and addressed to the CHMP Chairman. Extension may be justified for instance based on a new analysis of data from previously submitted studies, a need to re-validate an assay including experimental studies or analysis of additional patient samples employing an improved analytical method. The clock would be stopped at Day 180 and restarted at Day 181, a maximum of two months after receipt of the LoOI [9].

The timelines defined in the Notice to Applicants limits the evaluation procedure to 210 days. Between Day 181 and Day 210, the 'opinion' is prepared. Typically, scientific opinions of the CHMP are adopted by consensus. If a consensus is not possible, the rules require an absolute majority of the members of the CHMP (i.e. favorable votes by at least half of the total number of Committee members eligible to vote plus one) [10]. Following adoption of the 'opinion' the Assessment Report is finalized. At marketing authorization application submission and during the assessment procedure ('pre-opinion') only the English language version of the Product Information is reviewed. However, within five days 'post opinion' the Applicant should provide the final English language version of the Product Information along with the translations on all other EU languages for a linguistic review.

During Day 215 to Day 229, the Member States check all translations. The Applicant sends final translations incorporating Member States' comments to the EMA by Day 232. After a final check for implementation of comments, the EMA compiles the 'opinion' and Annexes in all languages and send final versions to the EC, Members of the Standing Committee (see below) and the Applicant by Day 237
(27 days after opinion). By Day 246, the Applicant should supply to EMA one final full color 'worst-case' mock-up of outer and immediate packaging for each pharmaceutical form [11].

\section{EC and the Decision-Making Process}

The EMA is not the authority that is responsible for enacting legally binding national licenses. Instead, the EC is accountable for such decisions.

The EC is one of the three major institutions involved in the EU legislation and the administrative driving force of the EU responsible for implementing treaties, policies and initiating legislation as well as grant of marketing authorization according to 'centralized procedure' [12-14,32].

The EC is divided into several departments and services. The departments are known as Directorates-General (DGs). Each DG is classified according to the policy it deals with and subdivided into 'directorates' and 'units'; these different organizational levels are headed by a director-general, a director and a head of unit respectively [15]. For medicinal products for human use, the responsible department is the one for health and consumer protection (Health and Consumers Directorate General, SANCO). Within the 'Health systems and products' department, the unit 'D5-Medicinal products authorizations, EMA' is in charge of approval related activities.

The other European institutions with which the EC shares executive powers are the Council and the European Parliament (EP). The Council reflects the elected governments of the individual Member States and the EP represents an elected body with limited legislative role and EC control function. Together, these institutions conduct 'Ordinary Legislative Procedure' for EU policies and laws, based on the same weight transferred to EP and Council [12,14-16].

For new registrations of human medicines following transmission of a favorable EMA 'opinion' to the EC, the second phase of the procedure - the 'Decision-Making Process' (DMP) - takes place. The following documents are annexed to the 'opinion' (Assessment Report) [17]:

\section{- $\quad$ ANNEX I (SPC)}

- ANNEX II particulars of the

- Manufacturer of the active substance and manufacturing authorization holder responsible for batch release

- Conditions of the marketing authorization

- Specific obligations to be fulfilled by the marketing authorization holder

- ANNEX III

- Labeling in all EU languages (A)

- package leaflet (B)

The DMP regulations are included in the collection of EU legislation in the pharmaceutical sector (Reference documents - 'Eudralex Volume 2 - Pharmaceutical Legislation Notice to applicants and regulatory guidelines medicinal products for human use'). Specifically, in Volume 2A 'Procedures for marketing authorization' the DMP is elaborated in Chapter 6 concerning 'Decision making procedure for the adoption of Commission decisions' [18].

During the DMP, as part of the oversight function vis-à-vis the EMA, the EC scrutinizes draft CHMP opinions from the perspectives 
of different national regulatory agencies prior to its adoption and primarily verifies that the marketing authorization complies with EU legislation [7]. Furthermore, the DMP is correlated with public health concerns as well as risk mitigation associated with the introduction of new medicines in the single EU market and includes product information review. But neither further linguistic review nor continued scientific re-assessment is intended, which would be beyond the scope of the capabilities of the EC.

After receipt of the EMA assessment documents, the EC has 15 days to prepare a draft decision. During this period, the Commission DGs are consulted on the draft marketing authorization decision. As far as the workflow is concerned, for matters in which the EC cannot act independently, the issue must be referred back to the EMA, where it is re-examined by the expert committee. Upon discussion with EMA / CHMP the matter or concern on the benefit / risk assessment may be resolved by providing explanations or changes to the opinion. In addition to the EMA input, to render a valid administrative act that is binding on all Member States, continued Member State consultation is mandatory [19]. During this stage no direct interaction and exchange of information with the Applicant is foreseen.

Within the EU, tasks and functions are frequently assigned to the EC. Inside the EC specialized tasks are again assigned to expert groups. The EU legislation deliberately allows the delegation of legal power and competencies. As such the EC is assisted in the DMP by committees composed of representatives from EU Member States. Under Article 202 of the Treaty establishing the European Community, a 'Comitology' procedure was implemented. Comitology refers to a permanent advisory body of representatives of the Member States (Standing Committee) which is chaired by the Commission. In addition, Article 87 of Regulation 726/2004 states that 'The Commission shall be assisted by the Standing Committee on Medicinal Products for Human Use set up by Article 121 of Directive 2001/83/EC [...]'.

In principle, the EC may be assisted by the following four committee procedures [20]:

Advisory (purely advisory role and its opinion is non-binding to the EC)

Management (can only block the EC proposal by qualified majority, which will then be submitted to the Council)

Regulatory (a proposal is referred to the Council, unless it is endorsed by a qualified majority of Member States' votes)

Regulatory procedure with scrutiny (if the EC draft measures obtained a positive opinion from the Committee, they shall be submitted for scrutiny to the EP and the Council. If neither the Council nor the EP opposes the draft, the Commission shall adopt the measures.

Criteria for the selection of a certain Comitology procedure for the adoption of implementing measures are stipulated in a specific Council Decision, indicating in which cases an act can introduce a procedure for its implementation [21].

The EC maintains a 'Comitology Register' that contains background information and documents relating to the work of these committees, including all documents forwarded to the EP for information purposes or scrutiny [22]. Concerning new registrations, a 'Regulatory procedure with scrutiny' may be applicable. Under this procedure, the EC's draft decision is sent to the national representatives via the Standing Committee. Comments are due within 22 calendar days. If urgent, shorter time limits may be set by the EC (see Article 35 EC 726/2004). Usually organized as a written procedure, at this phase observations may be recorded and distributed among the Member States. A Standing Committee meeting may be scheduled or in case new scientific questions arise which have not been addressed in the EMA opinion, the procedure may be suspended and request is made to the EMA for a further opinion. Should a Standing Committee meeting take place and the outcome may be favorable (qualified majority) the $\mathrm{EC}$ can proceed with the adoption of the decision. In case of a negative opinion, the decision will be communicated the Council. The Council may make a different decision, but so far has never happened.

Decisive action within the EC's Standing Committee on Medicinal Products for Human Use is also limited, because Member States maintain the right to block unwanted authorization decisions to the extent that a registration cannot be granted without the agreement of the EC and the Standing Committee [7].

In general, the Standing Committee processes large number of new applications per year, besides decisions regarding extensions, renewals, suspensions, revocations etc. Each of the Member States must inform whether they approve or reject / abstain [23]. The Head of the Unit processing and coordinating the consultation with the Standing Committee informs all Member States as well as the EMA and the Applicant rapidly upon completion of the Standing Committee procedure. The letter on the Draft Commission Decision typically states the date when the draft decision was submitted to the Standing Committee. Furthermore the communication contains a remark on whether a Member State has requested a plenary meeting (Article 10(3) c of 726/2004) or if a Member State has raised scientific or technical questions as per Article 10(4) of 726/2004. The letter acknowledges that the opinion of the Committee given 22 days post submission refers to the EC draft.

\section{The Adoption Phase - Generation of the Final EC Decision}

Following a favorable opinion, 15 days after the Standing Committee decision, the draft decision is adopted and the final Commission decision generated by the 'empowerment procedure' whereby the Director of DG SANCO, on behalf of the Commissioner, notifies the marketing authorization holder of the granting of the marketing authorization [14]. The decision is published in the Official Journal at monthly intervals and provides the license details, including the assigned registration numbers in the Community register. In the $\mathrm{EU}$, a marketing authorization is normally valid for a period of five years (except when a 'conditional marketing authorization' has been granted) from the date of notification of the EC decision. Applications for renewal must be made to the EMA at least six months before this five-year period expires [24].

\section{Role of the European Parliament -'Droit de regard'}

According to the current legislation, the EP (Committee on the Environment, Public Health and Food Safety) has a 'right of scrutiny' ('droit de regard') for draft implementing acts based on legislation decided jointly by the Council and Parliament (co-decision). Since 3 June 2008, the 'droit de regard' period for the Commission Decisions taken as part of the 'DMP' has been shortened to 7 days. Exempted from this shortened period of the 'droit de regard' are:

Draft Commission Decisions not in accordance with the scientific opinion of the EMA

Member States, during the vote, request that the draft Decision 
is discussed in a plenary meeting of the Standing Committee; or

- The opinion of the Standing Committee is unfavorable.

In practice, the additional 7 days of the 'droit de regard' following the vote by Member States is used to prepare the final Decision for adoption once the 7 days have expired with little impact on the overall duration $[24,25]$. 1.

The major steps and timelines at the EC are summarized in Figure

\section{Benchmarking EC Review Procedures}

Medicines evaluation histories as performed by the EMA are published in the European Assessment Reports (EPARs) which are displayed on the EMA web site (see section: Initial authorization documents, EPAR - Scientific Discussion). In terms of procedural issues, the EPAR heading relating to 'Steps taken for the assessment of the product' summarizes information on regulatory milestones achieved during the assessment process [26].

Because Standing Committee discussions are confidential, their outcomes are not disclosed [27]. Nevertheless, EC review time lines including information concerning Standing Committees procedures can be extracted from EPARs. By looking at the published records of licensed medicines in the EU, it is apparent that Standing Committee procedures have been rarely suspended. Examining more than 700 centrally authorized medicines as per Q2/2011, relatively few Standing Committee processes have led to delayed registrations. Extensions of the time required for granting a marketing authorization were seen in only around $2 \%$ of new applications. The estimated time frame is in the range of three months post 2 nd CHMP positive opinion. Delays due to suspended Standing Committee processes should take into account the recent shortening of the review time to 67 days. Previously, Regulation 2309/93 allowed 30 days for transmission of the EMA opinion to the EC, 30 days for preparation of Commission draft decision, 30 days for Standing Committee consultation and $30+$ days for issuance of the final decision; totaling at least $120+$ days.

A summary of the reasons for suspension of Standing Committee procedures is given in Table 1.

In principle legal, quality and safety/efficacy aspects could contribute to delays in timely EC approvals. Entry points for communication of concerns are either the EMA or the Standing Committee.

Legal reasons may lead to suspensions, for instance due to the proposed dispensing and classification of a medicinal product in the EU (Article 71 of 2001/83). Another issue could be associated with prescription status or the need for renewal of prescriptions or appropriateness of special/restricted prescription. Questions have also been posed in conjunction with the orphan drug status of medicinal products, which necessitate certain conditions for its designation and maintenance.

Quality aspects mattered only exceptionally to the degree that batch release testing had to be assured to be performed within the EU (Article 51(1) a).

Most often safety information played a major role in the EC review given that new Serious Adverse Events emerged or based on new information in the public domain or novel safety analysis new risks were identified which were beyond the scope of the scientific evaluation. In these cases, the Standing Committee suggested re-discussing the benefit/risk of a marketing authorization application.

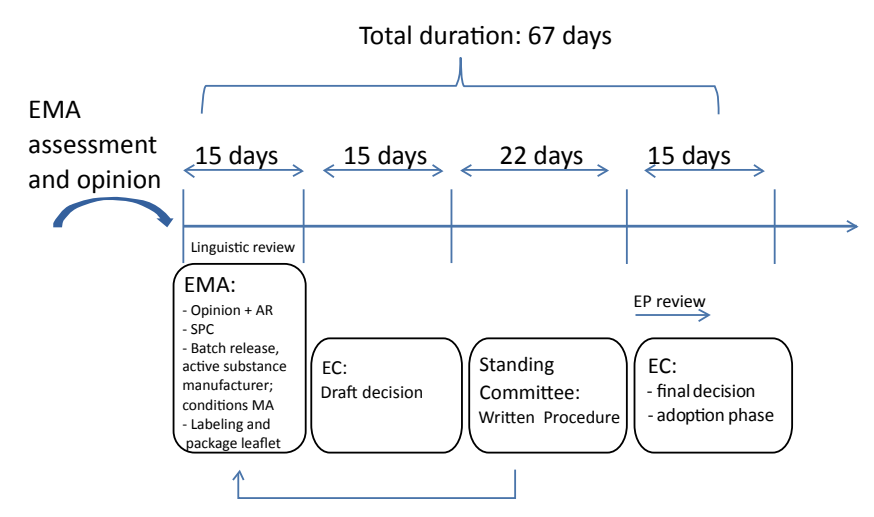

Figure 1: Overview of Standard Timelines for DMP at the EC

Following transmission of the EMA opinion, the Commission generates within 15 days the 'Draft decision' which is forwarded to the 'Standing Committee'; this consultation is a 22 day procedure; after receipt of the feedback from the Member States the Commision has another 15 days for approval; in parallel the $\mathrm{EP}$ has seven days for accomplishing its review.

Infrequently new efficacy or safety data relevant for the benefit/risk assessment have come up in the EC approval. In case of a biosimiliar evaluation (eg. Ratiograstim) the Standing Committee requested inclusion of additional data from a similar nationally authorized form in the registration dossier. The Standing Committee suggested that safety information provided for authorization of the similar product and information collected post authorization were relevant and applicable to the biosimilar application. However, upon reexamination of data from a pharmacokinetic and pharmacodynamic study, the EMA concluded that the original opinion was unaffected by the new (historical) results and that these data did not change the efficacy results. An additional request by the Standing Committee for GCP inspection was not substantiated due to adherence of conducted studies to GCP as recognized by the EMA [28].

In a recent case, an implementation decision not to grant marketing authorization was made for an advanced medicinal product (Glybera) for treatment of lipoprotein lipase deficiency. This negative EC decision was given on grounds of a negative EMA opinion following re-examination of an initial negative CHMP opinion. CHMP maintained its recommendation not to grant a marketing license. Of note, the Standing Committee, after discussion of the refusal as recommended by the CHMP, was indecisive and requested additional information from the CHMP. This expert committee maintained its refusal recommendation. It remains to be seen how the EC will respond and whether the Council may change this decision. Of interest, the Committee for Advanced Therapies (CAT) was also involved in the assessment of this medicinal product. Taking into account the initial negative opinion provided by the CAT during the re-examination, the CAT concluded that concerns could be addressed with additional post-marketing studies $[29,30]$. Clearly public health matters and availability of new medicine for unmet medical need may contribute to the final decision.

\section{Conclusions}

The EU has implemented a 'brace and belt' strategy for approval of new drugs whereby the EMA is responsible for performing essentially the scientific evaluation of new applications. This is followed by ECdriven additional administrative measures to assure implementation of approval decisions across the Member States. Over the years, no major obstacles in terms of processing could be identified. Although in some 


\begin{tabular}{|c|c|c|c|}
\hline \multicolumn{2}{|c|}{ Areas of grounds for suspension } & & $\begin{array}{l}\text { Approximate time period required for approval }{ }^{*} \\
\text { Aricliam [Duloxetine]: } 140 \text { days } \\
1^{\text {st }} \text { CHMP opinion - } 24 \text { March2004; } \\
\text { EC approval - } 11 \text { August } 2004: 140 \text { days }\end{array}$ \\
\hline Safety & Emerging serious $A E$ & 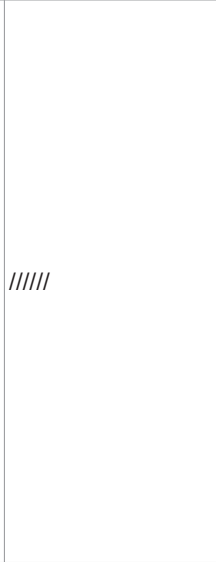 & $\begin{array}{l}\text { Aricliam [Duloxetine]: } 140 \text { days } \\
1^{\text {st }} \text { CHMP opinion - } 24 \text { March2004; } \\
\text { EC approval - } 11 \text { August } 2004: 140 \text { days } \\
\text { Ferripox: [deferpone] :210 days } \\
1^{\text {st }} \text { CHMP opinion - } 28 \text { Jan } 1999 \\
\text { EC approval - } 25 \text { Aug 1999: } 210 \text { days } \\
\text { Macugen [pegaptanib]:135 days } \\
1^{\text {st }} \text { CHMP opinion: } 15 \text { Sept } 2005 \\
\text { EC approvaxl: } 31 \text { Jan } 2006 \\
\text { Tyverb [lapatinib ]: } 130 \text { days } \\
1^{\text {st }} \text { CHMP opinion : } 13 \text { Dec } 2007 \\
\text { EC approval: } 24 \text { April } 2008 \\
\text { Yentreve [duloxentine]: } 135 \text { days } \\
1^{\text {st }} \text { CHMP opinion: } 24 \text { March } 2004 \\
\text { EC approval: } 11 \text { Aug } 2004\end{array}$ \\
\hline Efficacy & $\begin{array}{l}\text { New efficacy data for benefit risk ratio } \\
\text { Insufficient evidence to show benefit }\end{array}$ & /I & $\begin{array}{l}\text { Ratiograstim [filgrastim]: } 210 \text { days } \\
1^{\text {st }} \text { CHMP opinion ; } 21 \text { Feb } 2008 \\
\text { EC approval : } 15 \text { Sept } 2010 \\
\text { Glybera [alipogenetiparvovec] } \\
1^{\text {st }} \text { CHMP opinion: } 23 \text { June } 2011 \\
2^{\text {nd }} \text { CHMP opinion (re-examination): October } 2011 \\
\text { EC: re-evaluation in restricted patient group } 22 \text { January } 2012 \\
3^{\text {rd }} \text { CHMP opinion (re-evaluation): } 19 \text { April } 2012 \text { negative }\end{array}$ \\
\hline Legal & $\begin{array}{l}\text { Prescription status (acc. to Article } 71 \text { of Directive 2001/83); supply } \\
\text { for products through pharmacies only } \\
\text { Non acceptable convenience pack with several different medical } \\
\text { products co-packaged in single presentation } \\
\text { Designation as orphan medicinal product }\end{array}$ & IIIII & $\begin{array}{l}\text { Kentera [Oxybutynin]: } 210 \text { days } \\
1^{\text {st }} \text { CHMP opinion }-20 \text { Nov } 2003 \\
\text { EC approval - } 18.6 .2004 \\
\text { Litak [Cladribine]: } 170 \text { days } \\
1^{\text {st }} \text { CHMP opinion } 22 \text { Oct } 2003 \\
\text { EC approval: } 14 \text { Apr } 2004 \\
\text { Panteca [pantoprazole]: } 110 \text { dyas } \\
1^{\text {st }} \text { CHMP opinion - } 19 \text { Feb } 2009 \\
\text { EC approval - } 12 \text { June } 2009 \\
\text { Prolia [denosumab]: } 160 \text { days } \\
1^{\text {st }} \text { CHMP opinion } 17 \text { Dec } 2009 \\
\text { EC approval; } 28 \text { May } 2010 \\
\text { Rebetol [ribavrin] } \\
\text { EC notified EMA on non acceptability of presentation during review } \\
\text { procedure } \\
\text { Votrient [pazopanib hydrochloride]: } 120 \text { days } \\
1^{\text {st }} \text { CHMP opinion: } 18 \text { Feb } 2010 \\
\text { EC approval:16 June } 2010\end{array}$ \\
\hline Quality & Batch release arrangements & 1 & $\begin{array}{l}\text { Foresto [teriparatide]:170 days } \\
1^{\text {st }} \text { CHMP opinion: } 18 \text { Dec } 2001 \\
\text { EC approval: } 10 \text { June } 2002: 170 \text { days }\end{array}$ \\
\hline
\end{tabular}

"based on evaluation of more than 700 licensed drugs as per EPARs (Q2/2011); see

http://www.ema.europa.eu/ema/index.jsp?curl=pages/medicines/landing/epar_search.jsp\&mid=WC0b01ac058001d125

"Registration dates are derived from information as given in the EPARs and may slightly deviate from the published 'Date of notification' and the information provided in the Community Register which relates to 'Close date procedure'

Values were rounded and approximate duration is suggested in days

Table 1: Overview - Standing Committee procedures and approximate DMP timelines for centrally authorized medicinal products.

exceptional cases approvals were more time consuming than average their low incidence in total suggests a lack of intentional means.

The overall complexity of the organizational workflows and time requirements at the EC with little transparency calls for further simplification and streamlining. Besides the recent shortening of the EC review period further reduction of Member States time requirements and influence appears difficult to implement.

The obligation for involvement of national representatives at the EC level usually does not reflect important new scientific considerations in view of incorporation of Member State representatives already during review of new applications in the EMA/CHMP. It could be argued that the repeated Member State review may not add value to the overall quality of the assessment while timelines are unnecessarily extended prior to licensure. Yet different aspects and insights from the public health point of view could be leveraged from this expert group for the sake of overall robustness of the regulatory output.

Although desirable, in EMA may not evolve to a true supranational agency carrying out the scientific evaluation and issuing licenses, likewise to National Competent Authorities across the Member States. However, transferring administrative expertise from the EC to the Agency may be easier to achieve than vice versa. But most likely, the 
Community will continue to have two separate organizations jointly accomplishing licensure.

In recognition of the adminstrative burden associated with the two systems ultimately a single health agency should be envisioned and installed covering both scientific and executive tasks related to drug approval. Also, a certain degree of inclusion of the Applicant in the set of activities and sharing of information between the stakeholders would enlighten the characteristics of this 'black box' process. In this respect, the US may serve as a model against the background that there is one institution ('The Department of Health and Human Services') which is the principle agency for health protection of the domestic population. Consisting of several offices and operating divisions, the Food and Drug Administration (FDA) is the health agency who has oversight of drug evaluation and regulatory approval, including issuance of US license numbers in accordance with the applicable legislation. However, it must recognised that the US federal system may not be comparable to the indvidual member states as existing in the EU. Nevertheless, it represents a single organziation effectively administrating scientific assessment as well asregulatory approval [31].

\section{Acknowledgment}

I would like to thank Dr. R. Peck for his critical review of the manuscript

\section{References}

1. http://ec.europa.eu/health/files/eudralex/vol-1/reg_2004_726_cons/ reg_2004_726_cons_en.pdf

2. http://www.ema.europa.eu/ema/index.jsp?curl=pages/about_us/general/ general_content_000094.jsp\&mid=WC0b01ac0580028c79

3. http://www.ema.europa.eu/ema/index.jsp?curl=pages/about_us/ general/general_content_000217.jsp\&murl=menus/about_us/about us.jsp\&mid=WC0b01ac0580028c77

4. http://www.ema.europa.eu/docs/en_GB/document_library/Press_ release/2012/04/WC500126142.pdf

5. http://www.emea.europa.eu/docs/en_GB/document_library/Brochure/2011/03/ WC500104234.pdf

6. http://www.ema.europa.eu/docs/en_GB/document_library/ Presentation/2009/11/WC500007626.pdf

7. Gehring T, Krapohl S (2007) Supranational regulatory agencies between independency and control: the EMEA and the authorization of pharmaceuticals in the European Single Market. Journal of European Public Policy 14: 208-226.

8. http://ec.europa.eu/health/files/eudralex/vol-2/a/chap4rev200604_en.pdf

9. http://www.ema.europa.eu/docs/en_GB/document_library/Regulatory_and_ procedural_guideline/2009/10/WC500005056.pdf
10. http://www.ema.europa.eu/docs/en GB/document library/Regulatory_and procedural_guideline/2009/10/WC500004181.pdf

11. http://www.emea.europa.eu/docs/en_GB/document_library/Regulatory_and procedural_guideline/2009/10/WC500004182.pdf

12. http://www.chcs.org.uk/eu-law-making-process.htm

13. http://www.law.duke.edu/lib/researchguides/europe.html

14. http://europa.eu/legislation_summaries/institutional_affairs/institutions_ bodies_and_agencies/010004_en.htm

15. http://europa.eu/about-eu/institutions-bodies/index_en.htm

16. http://www.europarl.europa.eu/aboutparliament/en/0080a6d3d8/Ordinarylegislative-procedure.html

17. http://ec.europa.eu/health/authorisation-procedures-centralised_en.htm

18. http://ec.europa.eu/health/files/eudralex/vol-2/a/vol2a_chap6_2005-11_en.pdf

19. Kidd D (1996) The International Conference on Harmonization of Pharmaceutica Regulations, the European Medicines Evaluation Agency, and the FDA: Who's Zooming Who? Indiana Journal of Global Legal Studies 4: 10.

20. http://ec.europa.eu/transparency/regcomitology/index.cfm?do=FAQ.FAQ

21. http://eur-lex.europa.eu/LexUriServ/LexUriServ.do?uri=CONSLEG:1999D046 8:20060723:EN:PDF

22. http://ec.europa.eu/transparency/regcomitology/index.cfm

23. http://www.ema.europa.eu/ema/index.jsp?curl=pages/regulation/q_and_a/q_ and_a_detail_000038.jsp\&mid=WC0b01ac0580023e7c

24. http://ec.europa.eu/health/documents/archives/2009_en.htm

25. http://page2rss.com/de56a40cedc4e65c358647c13 ba06556/4618881_4622990/droit-de-regard-important-notice-to-stakeholdersfollow-up-to

26. http://www.ema.europa.eu/ema/index.jsp?curl=pages/medicines/landing/ epar_search.jsp\&mid=WC0b01ac058001d125

27. http://ec.europa.eu/health/files/pharm_stand_comm/2011_09_13_human_ scrutiny.pdf

28. http://www.ema.europa.eu/docs/en_GB/document_library/EPAR_Public_ assessment_report/human/000825/WC500047793.pdf

29. http://www.amtbiopharma.com/news/137/182/Amsterdam-MolecularTherapeutics-Announces-European-Commission-Delays-Decision-onGlybera-Marketing-Authorisation-And-Requests-Further-Information-Fromthe-CHMP.html

30. http://www.ema.europa.eu/docs/en_GB/document_library/Summary_of opinion_Initial_authorisation/human/002145/WC500125710.pdf

31. http://www.hhs.gov/about/index.html 